Results

- Positive response with hearts used to record thoughts, hopes, ideas, aspirations, dreams.

- Hearts taken home or, for bereaved people, the blue hearts create a meaningful keepsake.

- Blue heart conversations have enabled a visit from a horse, a recorded message from a celebrity and has opened the door to many conversations between those who are dying and their loved ones.

Conclusion A simple idea successfully translated in to practice with very little cost but incredible benefit. Empowers people who use our service to share what truly matters to them and has enabled them to achieve, in some cases, what they never dreamed possible.

\section{P-36 START THE CONVERSATION (STC) - A COLLABORATIVE COMMUNITY APPROACH TO END-OF-LIFE DISCUSSIONS}

Christine Novelli. Isabel Hospice, Welwyn Garden City, UK

\subsection{6/spcare-2021-Hospice.57}

Background Advance care planning (ACP) is increasingly recognised as an integral part of achieving excellence at the end of life, but death and dying are not easy conversations to have, and as such the reluctance to talk about these issues increases the likelihood that a person's preferences will not be discussed or met (Byw Nawr, 2016). The Compassionate Communities Charter recognises that raising awareness and promoting palliative and end-of-life care needs to be part of all aspects of health and social care and not the sole responsibility of those providing the services, encouraging communities to support people and their families who are dying or living with loss.

An end of life task and finish group consisting of NHS providers, local hospice and County Council representatives was established to co-produce a simple yet effective solution.

Aims To reduce the barriers to advance care planning conversations by offering tools and opportunities to empower communities to drive the conversation amongst themselves and their health care providers.

Method

- Created a leaflet and poster suggesting topics to think about, and introduce ACP.

- Developed an informative website - starttheconversationtoday. org.uk - launched in Dying Matters Week 2021.

- Downloadable ACP template.

- Host free two-hours STC workshops.

- Run monthly death cafés.

- Identify and train partners and community champions to promote and engage further.

Results to date 2000 leaflets and 200 posters distributed around target area; 60 participants at STC workshop; engaged four partners; 188 hits on the website.

'I understand much more now about what and how things happen around death, and how to be better prepared in advance so that it's easier for everyone.'

Conclusions Early results are showing increased interest in: end-of-life and advance care planning conversations, addressing taboos and expectations of death and dying, and engaging new partners.

\section{P-37 SUPPORTING ADVANCE CARE PLANNING FOR PEOPLE WITH LEARNING DISABILITIES IN THE WYRE FOREST CARE HOMES}

${ }^{1}$ Caitlyn Adkins, ${ }^{2}$ Claire Smith. ${ }^{1} K E M P$ Hospice, Kidderminster, Worcestershire; ${ }^{2}$ Herefordshire and Worcestershire Heath and Care NHS Trust, Wyre Forest, Worcestershire

\subsection{6/spcare-2021-Hospice.58}

Background Advance care planning (ACP) empowers people to think about what is important to them and provides an opportunity to record their wishes for future care (Gold Standards Framework, 2018). NICE recognise that people growing older with a learning disability should have the same opportunities as everyone else to plan for the future (National Institute for Health and Care Excellence, 2018). Working collaboratively allowed the ACP Facilitator and Learning Disabilities Liaison Nurse to provide better opportunities for ACP discussions.

Aims To provide people with a learning disability living within a care home in the Wyre Forest with an opportunity to explore ACP; ensuring we capture what is important to people and record a summary of clinical recommendations for care and treatment on a ReSPECT form (Reuscitation Council UK, 2021). Provide support and training to the care home staff to increase their knowledge and understanding of ACP and effective communication skills. Ensuring that we include everyone that should be involved in ACP discussions was vitally important and as shown in the LeDeR review not always happening within practice (LeDer, 2020-21).

Methods In collaboration with the care homes, relevant healthcare professionals and advocacy services where appropriate to provide residents and their loved ones opportunities to have open and honest ACP discussions. Reviewing all previously recorded ACP to ensure completed correctly and valid.

Results Increased uptake of ReSPECT forms and ACPs for residents within the local learning disability care homes. Development of staff communication skills and understanding of ACP. Good verbal and written feedback following teaching sessions and regarding the support provided.

Conclusion ACP is recognised as having a very important role for empowering people to think about what is important to them. These discussions are just as important for people who have a learning disability, and they should be given the same opportunities to have open and honest discussions (PCPLD Network \& NHS England, 2017). We must ensure we involve all appropriate people. This collaborative working approach has allowed different skills and knowledge to work together to provide better opportunities for residents.

\section{P-38 NO BARRIERS HERE! ADVANCE CARE PLANNING AND PEOPLE WITH INTELLECTUAL DISABILITIES}

${ }^{1}$ Gemma Allen, ${ }^{2}$ Jed Jerwood, ${ }^{3}$ Mr Vince Peters, ${ }^{3}$ Samantha Reeves, ${ }^{3}$ Sarah Offley. ${ }^{1}$ Mary Stevens Hospice, Stourbridge, UK; ${ }^{2}$ Institute of Clinical Sciences, University of Birmingham, Birmingham, UK; ${ }^{3}$ Dudley Voices for Choice, Dudley, UK

\subsection{6/spcare-2021-Hospice. 59}

An easy read version of the abstract to accompany the oral presentation is available from the first named author.

An abstract for the oral presentation $(\mathrm{O}-8)$ is available on page A3 of this supplement. 